\title{
Correction to: Health-related quality of life and its socio-economic and cultural predictors among advanced cancer patients: evidence from the APPROACH cross-sectional survey in Hyderabad-India
}

Jean Jacob ${ }^{1,2}$, Gayatri Palat ${ }^{1}$, Naina Verghese ${ }^{3}$, Priya Kumari ${ }^{1}$, Vineela Rapelli ${ }^{1}$, Sanjeeva Kumari ${ }^{1}$, Chetna Malhotra ${ }^{3}$, Irene Teo ${ }^{3}$, Eric Finkelstein ${ }^{3,4}$ and Semra Ozdemir ${ }^{3,4^{*}}$

\section{Correction to: BMC Palliat Care}

https://doi.org/10.1186/s12904-019-0465-y

Following publication of the original article [1], the corresponding author reported an error on the name of the fourth author. "Priya Chandran" should be "Priya Kumari".

\section{Author details}

${ }^{1} \mathrm{MNJ}$ Institute of Oncology and Regional Cancer Center (MNJIORCC), Hyderabad, Telangana, India. ${ }^{2}$ Department of Supportive Care, Princess Margaret Cancer Centre, University Health Network, Toronto, Canada. ${ }^{3}$ Lien Centre for Palliative Care, Duke-NUS Medical School, Singapore 169857, Singapore. ${ }^{4}$ Saw Swee Hock School of Public Health, National University of Singapore, Singapore, Singapore.

Published online: 23 January 2020

\section{Reference}

1. Jacob J, Palat G, Verghese N, Kumari P, Rapelli V, Kumari S, Malhotra C, Teo I, Finkelstein $\mathrm{E}$, Ozdemir $\mathrm{S}$. Health-related quality of life and its socioeconomic and cultural predictors among advanced cancer patients: evidence from the APPROACH cross-sectional survey in Hyderabad-India. BMC Palliat Care. 2019;18:94.

\footnotetext{
The original article can be found online at https://doi.org/10.1186/s12904019-0465-y

* Correspondence: semra.ozdemir@duke-nus.edu.sg

${ }^{3}$ Lien Centre for Palliative Care, Duke-NUS Medical School, Singapore 169857, Singapore

${ }^{4}$ Saw Swee Hock School of Public Health, National University of Singapore,

Singapore, Singapore

Full list of author information is available at the end of the article
}

C The Author(s). 2020 Open Access This article is distributed under the terms of the Creative Commons Attribution 4.0 International License (http://creativecommons.org/licenses/by/4.0/), which permits unrestricted use, distribution, and reproduction in any medium, provided you give appropriate credit to the original author(s) and the source, provide a link to the Creative Commons license, and indicate if changes were made. The Creative Commons Public Domain Dedication waiver (http://creativecommons.org/publicdomain/zero/1.0/) applies to the data made available in this article, unless otherwise stated. 